\title{
Inmigración judía a Chile desde la Alemania Nazi
}

\author{
Jewish immigration to Chile from Nazi Germany
}

Eva Goldschmidt

evagoldschmidt@yahoo.com

Escritora

Chile

\section{Resumen:}

La inmigración judía durante la época del Holocausto se hizo difícil porque antes de 1933 las puertas de diferentes países empezaron a restringirse por depresión económica, y después de 1933 se restringieron aún más por antisemitismo, resultando en una fobia anti-inmigratoria. Entre 1918 y 1933 las puertas de Latino América estaban abiertas a la inmigración judía y a la inmigración en general, pero desde 1933 hasta 1945 solo se permitió la entrada de unos 84,000 refugiados judíos.

En Chile las circunstancias fueron diferentes. La elección presidencial a fines de 1938 cambió la historia de Chile. El presidente elegido, Pedro Aguirre Cerda, abrió la puerta a los refugiados, mientras otros países la cerraban. Su triunfo se debió al voto de los Nacis chilenos en circunstancias increíbles. Al final de su existencia los Nacis de Chile al mando de su jefe Jorge González von Marées criticaron la furia antisemita alemana y a los alemanes chilenos y a sus descendientes en Chile por no incorporarse al país en el que ya habían residido por tres generaciones. Nuestro pequeño Chile aceptó entre 13,000 y 15,000 judíos en los años del Holocausto.

Los inmigrante judíos, a quienes se les culpó de quitarles el trabajo a los chilenos, contribuyeron 
con nuevas industrias y métodos, fabricaron productos que antes debían importarse, ahorrando divisas a Chile.

Palabras Claves: Inmigración Judía Alemana a Chile - Holocausto - Alemania Nazi - Pedro Aguirre Cerda y la inmigración - Nazismo - Judíos en Chile.

\begin{abstract}
Jewish immigration during the Holocaust era became difficult because before 1933 the doors of different countries began to be restricted by economic depression, and after 1933 were further restricted by anti-Semitism, resulting in an anti-immigration phobia. Between 1918 and 1933 the gates of Latin America were open to Jewish immigration and immigration in general, but from
\end{abstract} 1933 to 1945 only about 84,000 Jewish refugees were allowed in.

In Chile the circumstances were different. The presidential election in late 1938 changed the history of Chile. The elected president, Pedro Aguirre Cerda, opened the door to the refugees, while other countries closed it. Their triumph was due to the vote of the Chilean Nationals in incredible circumstances. At the end of their existence, the Chilean Nacis under the command of their leader Jorge González von Marées criticized the German anti-Semitic fury and the Chilean Germans and their descendants in Chile for not joining the country in which they had already resided for three generations. Our little Chile accepted between 13,000 and 15,000 Jews in the Holocaust years.

The Jewish immigrants, who were blamed for taking the work of the Chileans, contributed new industries and methods, made products that had to be imported before, saving foreign currency to Chile.

Keyword: German Jewish immigration to Chile - Holocaust - Germany Nazi - Pedro Aguirre Cerda and immigration - Nazism - Jews in Chile. 


\section{Introducción:}

La historia de Emanuel Keller es bastante común para muchos alemanes judíos a fines de la década de los treinta que intentaron inmigrar a cualquier país que los recibiera. Keller se dió cuenta que ninguno de ellos quería recibirlo cuando trató de salir de Alemania en Septiembre de 1938. El once de Septiembre consiguió un número para su cuota para inmigrar a Los Estados Unidos. Al mismo tiempo pidió inmigrar a Australia en caso de que fallara la inmigración a Norte América. El 2 de Noviembre recibió una respuesta del Consulado Boliviano que necesitaban más papeles. El 3 del mismo mes obtuvo una carta del Consulado del Paraguay que decía que solo recibían a no judíos con capital. El 9 de Noviembre de 1938, la noche de Los Cristales Rotos, fue tomado prisionero por la policía alemana y llevado a un campo de trabajo. En ese tiempo si un prisionero podía conseguir una visa, los Nazis lo dejaban en libertad. Su madre, mientras él estaba en prisión, hacía las diligencias. El 29 de Noviembre recibió noticias del Consulado Cubano que necesitaban más papeles para inmigrantes judíos y a principios de Diciembre recibió una comunicación del Consulado de Los Estados Unidos que el número de su cuota era demasiado alta para poder salir de Alemania. Una organización judía vió la posibilidad de una inmigración de Keller a Chile. Le costaría el equivalente de 9.000 dólares hoy en día. Pero aún debía conseguir la visa. El 29 de Diciembre recibió la noticia desde Tel Aviv que la cuota desde Palestina estaba saturada, y el 30 del mismo mes obtuvo una respuesta del Consulado de Panamá que ese país había cerrado sus puertas a la inmigración judía.

Finalmente en enero de 1939 Keller consiguió una visa al Uruguay. Había escrito a diez consulados de ocho países en tres continentes diferentes. Se fue a Montevideo en el Conte Grande pero cuando llegó, las autoridades no dejaron entrar a los inmigrantes que tenían visas inválidas. Se les habría devuelto a Alemania, pero el recién elegido presidente de Chile, Pedro Aguirre Cerda, al ser notificado, les concedió permiso a los refugiados entrar a Chile. ${ }^{1}$

1Wojak, Irmtrud. (1994). Exil in Chile. Berlin, Germany: Metropol Verlag. 151-55. 
Otra historia es la de Sofía Simonsohn, entrevistada en Chile muchos años después de su llegada. Viajó a Berlín en 1938 para obtener una visa a cualquier país que fuera. Fue de embajada a embajada. En las puertas de muchas colgaban letreros que decían "No Hay Visas." Las embajadas que aún las ofrecían, el costo era de 1.000 dólares americanos en ese tiempo, que hoy en día tiene la equivalencia de 6.000. Era una cantidad que ella no tenía. Más tarde ella y su marido supieron que se podía conseguir visa en el Consulado de Cuba a 150 dólares. Enviaron el dinero y obtuvieron los documentos. Partieron a Cuba desde Liverpool el 18 de mayo de 1939 en el Orduña. Cuando el barco llegó a Cuba, los judíos con visas inválidas, como los Simonsohns, no pudieron entrar.

Los Simonsohns y otros pasajeros ilegales fueron trasbordados en alta mar a otro barco que iba de vuelta a Inglaterra. Anclaron en Balboa, Panamá, donde pudieron quedarse, gracias a las negociaciones del rabino local y al Comité del "American Jewish Joint Distribution." Tuvieron que pagar 150 dólares por persona. Vivieron en barrancas de la marina, mujeres en una, hombres en otra. Las autoridades no estaban preparadas de recibir setenta y tres pasajeros. Estaban en el trópico con breves lluvias torrenciales, con un terrible calor y humedad. Los Simonsohns estuvieron allí por tres semanas, pero hubo algunos que tuvieron que quedarse por más de un año.

En el barco a Cuba los Simonsohns se habían hecho de amigos chilenos quienes le presentaron al Sr. Gutiérrez, un chileno que les prometió enviarles una visa desde Chile. Así lo hizo y los Simonsohns pudieron embarcarse en La Reina del Pacífico, gracias a la bondad de un chileno que solo habían conocido por algunos días. ${ }^{2}$

La venta de visas inválidas y de alto costo en las diferentes embajadas y consulados fue un gran negocio en Europa, en que se aprovechaban de la desesperación de los judíos. Es un caso que vuelve a repetirse innumerables veces.

2 Sofía Simonsohns, entrevistada por Brigitte Altmann en Santiago, Chile. 


\section{Desarrollo}

El período entre 1933 y 1945 es una época tanto de antisemitismo como de depresión económica global. Es difícil para los judíos encontrar un país que los quiera aceptar. En 1933 con Hitler en el poder, los judíos de Europa, incluso los de Alemania, no están aún convencidos de que hay que emigrar. Esto lo dejan como último recurso que para la mayoría llega con la "Noche de los Cristales Rotos" en Noviembre de 1938.

La mayor parte de las naciones de América Latina estuvieron abiertas a la inmigración en general y judía en particular entre 1918 y 1933. Después de 1933, cuando más judíos tuvieron la necesidad de salir de Europa y buscaron refugio en Latino América y en otras partes, empezó la resistencia a dejarlos entrar. Entre 1933 y 1945 Latino América solo aceptó 84,000 refugiados judíos, la mitad de lo que había permitido entrar entre 1918 y 1933.

Según Eduardo Weinfeld, en su artículo El Antisemitismo en América Latina, éste apareció como efecto de la propaganda nazi. Muchas familias en este continente se habían sentido orgullosas de tener entre ellos a judíos. La Argentina y el Brasil habían favorecido su establecimiento en el continente hispano, pero después cambió. La América Latina imitó a las naciones totalitarias europeas. En 1939 hubo varias naciones en el continente que aplicaron principios racistas y nazistas en sus leyes de inmigración. En Colombia existió el decreto \#1927 que en 1938 impidió la entrada a "personas que hubieran perdido su nacionalidad de origen o cuyos derechos políticos o civiles hubieran sufrido limitaciones de cualquiera especie" sin que se mencionara la palabra “judío”. "En México sucedió lo mismo desde enero de 1939”. Para visitar un país latinoamericano o establecerse en él durante los años treinta y principios del cuarenta lo mejor era tener un certificado que uno pertenecía al partido nazista. ${ }^{3}$

A pesar de la restricción de la inmigración judía a Latino América, Eduardo Rauch en su artículo Latin American Jewry (Judería Latinoamericana) dice: "Si Latinoamérica no ha sido un gran lugar para el Judaísmo, ha sido un magnífico asilo para los judíos". 4

3 Weinfeld, Eduardo. (1940). El Antisemitismo en la América Latina. Judaica, 83, 201-208.

4 Leiken, Judith. (1987). The Jewish Presence in Latin America. Boston, MA: Allen and Unwin. 
Aquí tenemos algunos datos de inmigración por país:

Argentina, que había admitido 79.000 inmigrantes judíos entre 1918 y 1933, admitió solo 24.000 entre 1933 y 1943. Otros 20.000 judíos entraron ilegalmente. Brasil, que admitió 96.000 judíos entre 1918 a 1933, recibió unos 23.000 entre 1933 y 1941. México solo aceptó a 400 refugiados judíos entre 1933 y 1945, sin embargo permitió la entrada de 16.000 españoles entre 1938 y 1945 y dio más de 1.400 visas a refugiados polacos católicos entre 1939 y 1941. A Chile entraron 13.000 israelitas entre 1933 y 1939. La República Dominicana admitió a 645 judíos de 1938 a 1945 y emitieron alrededor de 5.000 visas a judíos europeos. Aunque la mayoría nunca se estableció allí, las visas les permitieron salir de Europa.

Bolivia aceptó a 20.000 judíos entre 1938 y 1941 gracias a los esfuerzos de Mauricio Hochschild, un magnate minero alemán israelita que tenía vínculos políticos con el presidente de Bolivia, Germán Busch.

En 1941 cuando en Europa se comenzó la matanza en masa de los judíos, algunos gobiernos latino americanos les emitieron pasaportes y visas. Con estos documentos a veces podían salir de Europa aunque no llegaran a su destino. En 1942 El Salvador envió 20.000 pasaportes que ayudaron a salvar vidas en Budapest en $1944 .^{5}$

En Chile hubo una diferencia. La elección del presidente Pedro Aguirre Cerda que gobernó entre fines de 1938 hasta su muerte en 1941, los años más críticos y difíciles para los judíos europeos de conseguir una visa. Las puertas de Chile se abrieron mientras las de otros países se cerraban. Chile recibió entre 13.000 y 15.000 hebreos entre los años 1933 a 1940. La gran mayoría que inmigró a Chile en ese tiempo se lo debió al presidente Pedro Aguirre Cerda, que quiso hacer de Chile un asilo para los perseguidos, "el asilo contra la opresión”. El presidente anterior, Arturo Alessandri había restringido la entrada de judíos a cincuenta familias por año.

5 US Holocaust Museum Encyclopedia, www.ushmm.org/wlc/en/article.php? ModuleId= 10007824, citado $16 / 7 / 2015$ 
Dos eventos nos indican el gran sentimiento humanitario de Aguirre Cerda y su buena voluntad para con los judíos. El primer evento permitió la entrada a Chile de sesenta y ocho refugiados que llegaron a Montevideo el primero de marzo de 1939 con visas ilegales que Uruguay no aceptó. Estuvieron detenidos por once horas hasta que el cónsul chileno garantizó al ministerio del exterior uruguayo que permitiría la residencia permanente de estos refugiados en Chile. De no haber sucedido ésto, habrían sido devueltos a Europa. ${ }^{6}$

El segundo evento sucedió mientras se reunía en Montevideo un Congreso Internacional de Democracias entre el 15 y el 20 de marzo, 1939. Dos barcos con refugiados llegaron a Montevideo desde Europa. El Conte Grande con ochenta y un pasajeros y el Cap Norte con veintisiete. Los inmigrantes estaban nuevamente en peligro de ser devueltos a Europa, pero Presidente Aguirre Cerda intervino por segunda vez y aceptó a los refugiados residir en Chile. Los representantes chilenos al congreso, Natalio Berman y otros, incluyendo el del partido Nazi habían enviado una petición al presidente chileno de recibir a estos viajeros y él contestó afirmativamente. $^{7}$

Tuve la suerte de poder entrevistar a dos inmigrantes que vinieron a Chile en el último viaje del famoso barco chileno Copiapó que salió de Hamburgo el 30 de Agosto de 1939, un día antes del comienzo de la guerra. Hamburgo se preparaba para una guerra inminente. Habían dos barcos que cruzarían el océano de Hamburgo a Valparaíso. Eran el barco chileno Copiapó y el transatlántico alemán Patria, de la línea Hapag. El gobierno prohibió la salida del Patria y por supuesto los pasajeros que ya no podían viajar en ese barco estaban desesperados de encontrar un lugar en el Copiapó que estaba con todas las cabinas ocupadas. Hubo pánico. Era para los pasajeros la última oportunidad de escapar del Nazismo y de la guerra.

Los motores del Copiapó comenzaron a funcionar, pero luego se apagaron. Los pasajeros sabían que podía venir la Gestapo y hacerlos bajar. Pero el Capitán Muñoz debía esperar órdenes para

6 La Hora. 2-12 de marzo 1939. Santiago de Chile.

7 Nes-El, Moshe. (1982). "Inmigración Judía a Chile durante 1929-1939." Coloquio, 4, 85-86. 
partir. Estaba dispuesto a doblar y triplicar el número de pasajeros para incluír a los del Patria, pero tendría que construir cabinas de emergencia y obtener más colchones, botes salvavidas y alimentos que podrían ser subidos al barco en Amberes, Bélgica. Eran un total de trescientos pasajeros y el personal tuvo mucho más trabajo. El Capitán Muñoz demostró su buen corazón. Según mi entrevistado Manfred Klein, gracias al Capitán se salvaron noventa judíos y entre ellos veinte niños. $^{8}$

Otro entrevistado, Werner Glass, que también viajó en el Copiapó, comentó que antes de salir de Alemania tuvo que pagar impuestos de salida y agregar más impuestos especiales por ser judío. Cobraban también derechos por tener una visa, derechos por vacuna, derechos para funcionarios de aduana, derechos para abordar, derechos para transportar sus cosas personales. Según él, la emigración judía fué un buen negocio para muchos. Si uno no tenía dinero, le era imposible emigrar. A estas alturas ya no se podía llevar dinero, ni joyas, ni colección de estampillas o monedas, ni cuadros. (Se pudo hacer todavía a principios de 1939.)

Una vez que la guerra empezó, fué cada vez mas difícil salir de Europa. Los diferentes países cerraron sus puertas a la inmigración judía, el gobierno alemán apenas permitía a los judíos emigrar y hubo problemas de transporte. Al entrar Italia a la guerra en junio de 1940 se cerró esa ruta y solo quedaron caminos indirectos para salir de Europa, como cruzando Siberia a Japón, que podría tomar meses. No se conseguían visas si no había una manera de salir de Europa. En julio de 1940, de sesenta personas con posibilidad de obtener visa, solo tres tuvieron una ruta para salir. El viaje a través de Siberia tomaba tanto tiempo que los documentos caducaban antes que el inmigrante llegara a su destino y debía volver a Europa. ${ }^{9}$

Un grupo de 36 refugiados quiénes habían viajado por Siberia desde Alemania y Polonia, llegó a Valparaíso, Chile, en el barco japonés Heil Maru. Se les negó la entrada y continuaron a Ecuador. No se sabe de su destino. ${ }^{10}$

8 Esta historia también la cuenta Víctor Farías en Los Nazis en Chile, Seix Barral, 2000.

9 New York Times. 17 de Julio 1940, 11

10 New York Times. 5 de enero 1941, 33 
A otro grupo con visas de Haití también se le negó la entrada después de meses de viajar por el mundo. Desde Hamburgo habían cruzado por tierra a Siberia y de allí a Japón donde tuvieron que esperar varias semanas para tomar el barco japonés Montevideo Maru. No pudieron desembarcar ni en Haití ni en Brasil ni en Montevideo, donde llegaron el 19 de Enero de 1941. Tampoco se conoce su destino. ${ }^{11}$

Además de ser difícil salir de Europa, era peligroso viajar, no solo porque los barcos enemigos se atacaban, sino también porque los océanos, incluso a lo largo de la costa latinoamericana, estaban llenos de minas flotantes. No había peligro de ser torpedeado o hundido cuando se viajaba en un barco de un país neutral o en barcos latino americanos, aunque siempre quedaba el peligro de las minas.

En diez días de guerra no solamente torpedos sino también minas hundieron un total de veintiséis barcos, cuatro de ellos a causa de minas flotantes alemanas. Durante un fin de semana, minas hundieron diez barcos más, cuatro de ellos de países neutrales. Uno se hundió tan rápido que no hubo tiempo de bajar los botes salvavidas. La explosión fue aterradora y muchos saltaron al agua en la oscuridad. Tres horas después un barco pescador danés recogió a diez sobrevivientes y una embarcación británica a otros tres. ${ }^{12}$ Esto es solo un ejemplo de la guerra en los océanos.

La elección de Pedro Aguirre Cerda se debió a un suceso extraordinario. Incluso los más optimistas pensaron que triunfaría la derecha con Gustavo Ross, el protegido del presidente de ese tiempo, Arturo Alessandri Palma. Pero el 5 de septiembre de 1938 los nacistas chilenos al mando de su jefe Jorge González von Marées intentaron un golpe de Estado que fracasó. Se creyó que el General Ibáñez, pro facista y candidato a la presidencia, estaba involucrado en la manifestación contra Alessandri. Ibáñez y González fueron apresados y desde la cárcel declararon la guerra contra Alessandri y Gustavo Ross. Su encarcelamiento hizo posible que

11 New York Times. 20 de enero 1941.

12 Trabajo. 21 de noviembre 1939. Santiago de Chile. 
Pedro Aguirre Cerda ganara la presidencia con los votos de los nacistas que ya no pudieron votar por el General Ibáñez y votaron por Aguirre Cerda. Él les había prometido poner en libertad a su jefe Jorge González si ellos votaban por él.

Aguirre Cerda, entonces pudo abrir las puertas de Chile a la inmigración judía. Una de mis entrevistadas, la Señora Gundi Spandau que había trabajado en el consulado chileno de Berlín antes de emigrar a Chile, me dijo: "las visas durante el gobierno de Aguirre Cerda llovían, mientras que fue difícil conseguirlas durante la presidencia de Alessandri”.

Judíos europeos que tenían dificultad en encontrar asilo en otros países, le escribieron al presidente chileno que los dejaran entrar. Clara Reisberg Adler que vivía en Argentina le pidió que dejara entrar a su hermano a quién habían tomado preso en Alemania e internado en el campo de concentración de Dachau por ser judío. Lo dejarían en libertad al conseguir una visa, por eso le pedía al presidente de darle asilo en Chile ya que Argentina había cerrado sus puertas a inmigrantes judíos. ${ }^{13}$ Otros también escribieron cartas de Francia como Rachel y Rudolf Feldmann y Eugenie Lorbeer el 10 de enero, 1939, habiendo oído de su bondad. ${ }^{14}$ En esos momentos el presidente estaba seguramente absorto en el terrible terremoto de Chillán que ocurrió el 25 de enero de 1939.

Más arriba mencioné que en los diferentes países se empezó a limitar la inmigración judía. Lo mismo había sucedido en Chile. Sus cónsules y funcionarios del ministerio de relaciones exteriores eran según Víctor Farías, ${ }^{15}$ muy antisemitas y tomaron cada oportunidad de restringir la entrada de judíos al país. Ya en 1927 el Jefe Consular de Chile, Luis E. Feliú M., escribió en una comunicación confidencial a todos los cónsules que "los asiáticos (especialmente los chinos y los sirios) y africanos eran indeseables, pero que los judíos eran aún menos deseables." Otra comunicación por el Ministro de Relaciones Exteriores Ríos Gallardo a estos representantes chilenos fue "que se abstuvieran de visar los pasaportes de los individuos mencionados

13 Wojak, Exil in Chile, 95.

$14 \mathrm{Ib}$.

15 Farías, Víctor. (2000). Los Nazis en Chile. Barcelona, España: Editorial Seix Barral. 
excepto... en casos muy señalados". ${ }^{16}$

Bajo el gobierno de Arturo Alessandri (1920-1924; 1932-1938), el ministerio recordó al cónsul de Berlín disminuir las visas a los semitas y el 4 de Julio de 1937 en la Circular Confidencial \#4 se pidió centralizar la inmigración judía en los consulados de Hamburgo con Álvarez de la Rivera, "un agresivo antisemita” (según Víctor Farías), y en París y Génova. ${ }^{17}$ El cónsul aseguró que solo entrarían a Chile gente "de primer orden y con suficiente capital para instalar nuevas industrias en Chile... y así se evitaría una inmigración poco deseable... individuos de esta raza por ninguna razón deberían entrar en nuestro país" ${ }^{\prime 18}$. Otros cónsules como los de Múnich y Stuttgart actuaban igual ya que tenían gran admiración por Hitler. En sus oficinas se veían cerros de solicitudes amontonadas porque querían demorar los trámites, lo que dificultó la inmigración a Chile. ${ }^{19}$

Miguel Cruchaga Ossa fue otro cónsul antisemita en Hamburgo que en 1940 solo concedió cinco visas para cristianos, cuarenta en tránsito para Bolivia y ninguna a judíos. ${ }^{20}$

Las circulares secretas a los cónsules a veces fueron enviadas por Carlos Errázuriz Ovalle, director del Departamento Circular. El 26 de abril de 1939 le escribió al cónsul de Praga, Montt Rivas (otro antisemita) que el departamento no deseaba la venida de judíos por ricos que fueran, a lo que el cónsul le contestó que las empresas de navegación estaban instruidas para no dar pasaje a nadie sin confirmación de su oficina, así la mayor parte de los pasaportes visados en enero y febrero quedarían sin efecto, y ésto en momentos tan críticos para los judíos europeos. ${ }^{21}$

Además de todas las circulares secretas enviadas en tiempos de Arturo Alessandri, el 23 de abril de 1938 se dictó el Decreto Supremo N 640 que suspendía desde esa fecha por un año la tramitación de solicitudes de inmigración con la excepción de los que ya tenían familia en el

16 Ibídem, 185

17 Archivo Nacional de Chile, Ministerio de Relaciones Exteriores. 4146. (1939). Departamento Consular.

18 Archivo Nacional de Chile. 4202.

19 Farías, Los Nazis en Chile.

20 Farías, Los Nazis en Chile, 201-203.

21 Archivo Nacional de Chile, Ministerio de Relaciones Exteriores. 4209. 
país. ${ }^{22}$

Otro gran antisemita fue el cónsul de Praga, Gonzalo Montt Rivas, que informaba a la SS de los judíos que le pedían visa, causando su persecución y su transporte a Theresienstadt. Según Víctor Farías, este representante chileno era "un antisemita compulsivo de convicciones inhumanas". En un oficio confidencial del 27 de julio de 1938 escribió al Ministerio de Relaciones Exteriores sobre los judíos:

"Van a Bolivia, porque otros países no los reciben, elementos sumamente peligrosos para nuestro país, que tratarán de quedarse en Chile antes de llegar a Bolivia...Se trata en casi su totalidad de judíos comerciantes que nada aportan al progreso...que no tienen otra patria que el dinero...son sumamente feos y en su eventual cruce con las razas aborígenes resultarán verdaderos partos de los montes...". 23

La Hora, en su edición del 30 de agosto de 1938, publicó un facsímil de una respuesta que el cónsul chileno en París, Viel, mandó a monsieur Ivel P., a su pregunta para informarse sobre requisitos para inmigrar a Chile. Fue lo siguiente: si él era judío sería inútil aplicar. Fue copiado de La Tournée Parisienne que lo reprodujo como un documento sensacional. Seguramente la órden venía de Chile.

Por todos estos casos de antisemitismo, los hebreos se beneficiaron con el cambio de gobierno a fines de 1938, con la elección de Pedro Aguirre Cerda. Desde el comienzo él mostró su buena voluntad con los judíos y abrió las puertas para su entrada. Se formó un Departamento de Inmigración, encabezado por Robinson Álvarez Marín y debido a la ampliación de la inmigración y a la desesperante situación en Europa, la oficina despachó mil solicitudes de

22 Ibídem, 4.134.

23 Farías. Los Nazis en Chile, 188.

Cuadernos Judaicos - ISSN: 0718-8749

N 33 Diciembre 2016 
ingreso, dando preferencia a los que ya tenían familiares en Chile. ${ }^{24}$ Ahora venían entre 400 a 500 inmigrantes por mes, mientras que durante el gobierno de Alessandri solo entraron unas cincuenta familias mensualmente. ${ }^{25}$ Mientras en Chile las puertas a la inmigración se abrieron con Aguirre Cerda, en otros países se cerraban. En México por ejemplo se suspendió su entrada.

En Brasil y Argentina, las dos naciones más grandes de Latino América, se oponían a una gran inmigración judía. En Argentina se habían preparado nuevas y más severas leyes en su contra durante la conferencia sobre refugiados judíos en Evián, Francia, en julio de 1938, en que treinta y dos delegados de diferentes países se reunieron. Todo con excepción de la República Dominicana solo expresaron excusas por no poder aceptar más inmigrantes. Argentina dió el pretexto de la mala situación económica pero el motivo real fue su antisemitismo. Insistía además que los inmigrantes se asimilaran y se convirtieran. Brasil, el país más grande de Latino América aceptó a 23.445 israelitas entre 1933 y 1942. Igual que en los otros países, su gobierno envió a los consulados una circular secreta, número 1.127 del 7 de junio de 1937 que prohibía que les dieran visa a los judíos. ${ }^{26}$ Y efectivamente si examinamos la inmigración hebrea a Brasil por año, vemos que en 1937 bajó de 3.418 del año anterior a 2.003 en el año que se envió la circular. En 1938 solo entraron 530. De 1940 a 1942 hay el menor número de inmigrantes porque fue muy difícil salir de Europa, los Nazis ya no dejaban emigrar, no había rutas de viaje directo durante la guerra y los diferentes países cerraron sus puertas. ${ }^{27}$

Funcionarios del gobierno chileno, políticos y el hombre común en Chile tenían temor a la competencia laboral. Decían que la emigración de comerciantes y corredores judíos les quitarían el trabajo a los chilenos. Es lo que se leía en los diarios y se discutía en el parlamento. Pero según Guggenheim, de la juventud llegada al país, la mayor parte se dedicó al trabajo manual, industrial y a la agricultura. ${ }^{28}$ Se habían preparado para este tipo de trabajo antes de emigrar. Muchos de

24 Nes-El. "Inmigración Judía a Chile durante 1929-1939".

25 Ibidem, 82.

26 Levine, Robert M. (1987).“Adaptive tragedies of Jews in Latin America”. In J. Leiken and G.W. Merkx (Eds.), The Jewish Presence in Latin America. Boston, MA: Allen an Unwin.

27 Lesser, Jeffrey. (1995). Welcoming the Undesirables, Brazil and the Jewish Question. Berkeley: University of California Press. 184.

28 Guggenheim, Carlos. (1942). Refugiados-Inmigrados-Nuevos Chilenos. Santiago de Chile: Imprenta la Sud 
mis entrevistados habían aprendido antes de emigrar, costura, carpintería, cuidado de niños, enfermería, electricidad, etc.

Esta inmigración fue beneficial para Chile, según Guggenheim, porque muchos inmigrantes trajeron capital y maquinarias para construir nuevas industrias, empleando a chilenos y enseñándoles nuevos métodos de trabajo.

Guggenheim señaló que de los 13.000 judíos que inmigraron a Chile, más o menos 1.000 se dedicaron a empresas industriales y ocuparon aproximadamente a cinco mil trabajadores chilenos. Esta cifra no incluyó a empleados comerciales ni domésticos. Con la llegada de los inmigrantes se fabricaron muchos productos en Chile que antes debían importarse. Para nombrar solo algunos: artículos de aluminio, hilanderías, somieres, especialidades de tejidos, etc. Se economizaron así grandes sumas de divisas.

Guggenheim también mencionó que de la población chilena un 22.1\% se dedicó a la industria, de los extranjeros, el 21\% y de los inmigrantes judíos, el 30\%. Los extranjeros dedicados a la industria y a la agricultura son del $31.80 \%$ y el de los refugiados el $35 \%$.

Se dijo que los asilados serían una carga para el estado chileno, pero fueron sus parientes, amigos y organizaciones del país o del extranjero los que sostuvieron a sus enfermos, viejos o pobres que entraron a Chile. Ingresaron miles de dólares de los Estados Unidos para ayudar a estas personas.

Para los 13.000 refugiados que llegaron a Chile entre 1933 y 1939, el comité israelita pagó 66.000 dólares en 1940 y de enero a mayo de 1941 otros 24.800 dólares, lo que da un total de 24.800 (que hoy en día serían aproximadamente 1.349. 204 dólares.) Además los inmigrantes al pedir una visa en los consulados, debían pagar por ellas, lo que también fue una entrada para Chile, y si salieron antes de que se les confiscara el dinero, lo trajeron al país y a veces nuevas 
maquinarias de trabajo. Cito una parte de una carta enviada del cónsul de Praga al Ministerio de Chile con fecha 22 de marzo de 1939:

"En febrero se visaron 96 pasaportes y 9 legalizaciones, lo que en dólares significaría una entrada de 757.71... (hoy en día el equivalente de 11.291 dólares). Un grupo muy interesante para nuestro país también recibió el visa este mes, se trata de fuertes capitalistas...llevan...5.000 libras esterlinas que se dedicarán a la agricultura... Este mes de marzo... acudieron miles de judios pidiendo permiso para poder ir a Chile. He dado como cincuenta visas de turismo, a gente rica... quieren el visa solamente para poder salir al extranjero...ahora las entradas del consulado cubren ampliamente el gasto que tiene el Fisco en este país... ". ${ }^{29}$

Es importante mencionar los aportes de la comunidad judía que llegó a Chile después de 1933 porque la prensa antisemita chilena, financiada posiblemente desde Alemania, anunciaba a gritos que los judíos eran solo "prestamistas, usureros y elementos de vida parasitaria", y asimismo algunos en el senado repetían que éstos no eran agricultores y que solo se dedicaban al comercio, y el público antisemita repetía todo ésto. En este contexto salió un importante informe del secretario Leiswitz de la embajada alemana en Chile diciendo que "no hay ningún ramo de la economía chilena en que los judios no estén representados en forma destacada". Para los israelitas en Chile este informe fue importantísimo, aunque no fuera esa la intención de Leiswitz. Fue escrito porque el Ministerio de Relaciones Exteriores de Alemania Nazi solicitó a sus representantes diplomáticos en el extranjero elaborar informes sobre el "problema judío" en sus respectivos países.

Cita Leiswitz algunos latifundios en el sur y la zona central de Chile en manos de judíos con una gran producción agrícola. Trabajaron también en regiones inhospitalarias que circundaban el

29 Archivo Nacional de Chile, siglo XX. Ministerio de RR.EE. 4.209. 
Lago Llanquihue, que se convirtieron en prósperos huertos y granjas que producían papas, mantequilla, miel, tabaco, forrajes. Muchos explotaban tierra en diversas regiones como Puerto Montt, Chillán, Talca, San Fernando y San Felipe. Asímismo, según la documentación en Santiago, Valparaíso y Concepción, los hebreos tenían fabricación de paño, seda y artículos de confección, como también fábricas de conservas, alimentos, plásticos, cristales, muebles, tostadurías de café, siendo algunos propietarios de importantes laboratorios farmacéuticos. Informó que solo en Santiago, las familias judías hacia 1938 habían establecido 141 talleres que empleaban a más o menos 5.500 obreros chilenos. Leiswitz mencionó igualmente la firma Mauricio Hochschild y Cía. Ltda., que según él era una de las mayores exportadoras de cobre, oro y azufre en Chile. Este informe escrito por un alemán antisemita y nazista, aunque no fuera su intención ayudar a los judíos, demostró que la inmigración israelita fue beneficiosa para Chile y que el judío no solo se dedicaba al comercio ni vivía exclusivamente en Santiago, como los detractores afirmaban. ${ }^{30}$

En un artículo que apareció en Judaica nos informamos que con la inmigración de 13.000 a 15.000 judíos ${ }^{31}$ que llegaron entre 1933 y 1944 se "crearon más de 1.500 industrias grandes y pequeñas que proporcionaron trabajo a unos 8.000 obreros y empleados chilenos" cosa que se comprobó por las autoridades tanto nacionales como municipales por impuestos, registros de patentes, el Ministerio de Fomento, etc.

Se había afirmado en algunos periódicos que estas 13.000 personas, entre ellos mujeres, niños y ancianos se habían comprometido a radicarse en el sur y dedicarse a la agricultura y que rompiendo este compromiso y viniéndose a Santiago habían creado un gran problema económico en la capital. Pero el informe $\mathrm{N}^{\circ} 34$ del 18 de enero de 1943 firmado por su ex jefe Jorge Garretón decía que el $95 \%$ de los judíos no se habían comprometido a ir a ningún lugar determinado ni trabajar en algo acordado. Solo a 879 hebreos de los 3.559 que llegaron entre enero y abril de 1940 en los vapores Augustus, Virgilio, Orduña y Santa María se les impuso que

30 Böhm, Günter. (1994). Judíos en Chile:un informe confidencial de la Embajada Alemana en Santiago, junio de 1939. Proceedings of the Eleventh World Congress of Jewish Studies 1993. XI.

31 Walter Laqueur estima que 15,000 judíos inmigraron a Chile. Generation Exodus (2000). Hanover. N.H.:

Brandeis University Press, 218. 
vivieran fuera de Santiago y que se dedicaran a la agricultura. Este número representó el 5\% de la inmigración total. $^{32}$

Según el informe, 469 de los inmigrantes vivían donde se les había pedido; 259 pidieron permiso para cambiarse de territorio ya sea por clima húmedo o por falta de trabajo o por necesidad de estar con otros miembros de la familia, y en la mayor parte de los casos el permiso fue concedido por la autoridad provincial. A 135 personas no se les pudo ubicar y 18 habían salido del país o muerto. Resumiendo, un total máximo de 394 personas estaban viviendo en Santiago sin tener el permiso, el 3\% de los 13.000 inmigrantes judíos. De éstos la mayoría, al escribirse este informe estaban dedicados a industrias productivas. Bien difícil explicar el tan usado "problema judío" en Chile. ${ }^{33}$ Solo los antisemitas podían mencionarlo o escribirlo en sus periódicos.

Según Mundo Judío, muchos de estos inmigrantes fabricaban en el país lo que antes se importaba, así se puede decir que su ocupación era importante para la industria chilena. Un gran número trabajó en empresas no judías como técnicos, ingenieros o directores. En la Banca de Chile no existían judíos y en la Bolsa de Comercio solo trabajaban dos corredores. ${ }^{34}$

\section{Reacción anti y pro judía de los chilenos a través de sus periódicos y de su congreso a la llegada de los prófugos israelitas que escaparon la Europa nazi. ¿Hubo antisemitismo?}

Los periódicos de la década de los treinta reflejan la controversia alrededor de la inmigración hebrea. El semanario Mundo Judío combatió los comentarios negativos en contra de los israelitas y rebatió vigorosamente a sus atacantes y a los simpatizantes nazis, estuvieran ellos en el Parlamento, la Iglesia Católica o escribiendo para la prensa.

Los debates más cortantes eran de los periódicos pro nazis como La Patria, Trabajo, Deutsche Zeitung für Chile y Jota (de la juventud nazi) contra Mundo Judío, Frente Popular (órgano del gobierno de Aguirre Cerda) y La Aurora de Chile , cuyo director fue Pablo Neruda. Existía un

32 Levy, Robert. (1948). El verdadero aporte a la economía chilena. Judaica, 166.

33 Ibídem.

34 Levy, Robert. (1938) Judíos en la Economía Nacional Chilena. Mundo Judío, 3 de noviembre, $1938,11$. 
periódico en lengua yidish, Unzer Leben, que también atacaba a los nazis, y un diario de la comunidad árabe, La Reforma, que ocasionalmente entraba en el debate.

Leyendo todos estos periódicos nos da una clara impresión que en Chile existía una prensa libre y los diarios expresaban los pensamientos chilenos abierta y vigorosamente. Defensores de los judíos y enemigos de los nazis se encontraban en todos los partidos. Entre los intelectuales pro israelitas sobresalía Gabriela Mistral y Pablo Neruda.

El Trabajo, diario del partido naci, escribe sobre una "invasión judía que amenaza a Chile". Según ellos se trata de la entrada de comerciantes e intelectuales, entre los últimos un gran número de médicos que representan una enorme amenaza para el país porque todos estos elementos intelectuales son de una ideología comunista "y aprovechan su calidad de hombres de ciencia para hacer en forma esbozada ...la más peligrosa de las propagandas de disolución social ...y la avalancha hebrea invadirá las profesiones liberales sobre todo la medicina" y como no tienen escrúpulos profesionales, desplazarán a los médicos y a otros profesionales del país. "Este peligro necesita ser atajado a tiempo",35. Años después el mismo diario gritaba "no más inmigración judía". 36

Pero el periódico más depravadamente antisemita e ignorante era el órgano del Partido Nacional Fascista La Patria, que no cesaba de pronunciar su oposición a los judíos: “ ¡La chilenidad peligra!, El judaísmo es una realidad trágica", "El gran peligro judío", "Llegada de judíos está convirtiendo a Chile en la Palestina de Sur América"37, "La inmigración de Judíos significa la ruina de Chile",38, "Los judíos son los vampiros de la sociedad” ${ }^{39}$, “iel comercio en manos de judíos!" 40 . Todas estas palabras recuerdan los gritos en Alemania de "Deutschland erwache" (Alemania despierta), “Die Juden sind unser unglück” (los judíos son nuestra desgracia).

35 Trabajo, 3 de agosto de 1938, 5.

36 Ibídem, 10 de febrero de 1941.

37 La Patria (Santiago de Chile). 10 de junio de 1939.

38 Ibídem, 24 de junio de 1939.

39 Ibídem, 8 de julio de 1939.

40 Ibídem, 21 de octubre de 1939. 
El mismo diario estaba por supuesto contra el gobierno que dejaba entrar a estos judíos. En su artículo "El gran Peligro Judío" escribió que desde la fecha que el Frente Popular tomó el poder, más de ocho mil israelitas habían llegado a nuestro país para establecer sus negocios después de haber sido expulsados de otros pueblos y que el gobierno no había tomado ninguna medida contra esto. Nuestro país necesita hombres de progreso decía, les damos la bienvenida a todos los extranjeros, pero es diferente con esta "invasión judía" que constituye una grave amenaza para la soberanía de Chile y para su futuro económico y político y que "como una avalancha devastadora se ha descargado sobre nuestra nacionalidad, acaparando todo el oro del mundo, controlando los órganos administrativos mediante sus agentes, dirigiendo la prensa y todos los medios de divulgación ideológicas en las masas...". 41

Mundo Judío había mencionado el 25 de marzo de 1937 que Alemania pagaba a periódicos en todo el mundo para defender sus acciones, 300 marcos por artículo. Había 307 de éstos que aceptaban pago del gobierno alemán. Alemania según Víctor Farías tenía por lo menos un control parcial en periódicos como El Pacífico de Arica, La Patria de Concepción, El Diario Austral de Temuco, La Prensa de Osorno, El Correo de Valdivia de Valdivia, La Cruz del Sur de Chiloé. Tuvieron un control completo en la publicación del Diario Alemán y la Deutsche Zeitung für Chile. ${ }^{42}$ En 1934 Alemania gastó para publicidad global 110 millones de marcos (un equivalente a 663.800.000 hoy en día.) Ningún país gastaba tanto en publicidad. Se estimaba que el gasto para Chile era entre 50.000 y 100.000 por mes que hoy en día equivaldría entre 350.000 y 600.000. ¿Habrá sido esa la razón por tantos artículos en contra de los judíos?

Como La Patria seguía con su extremo antisemitismo y crítica al gobierno de Aguirre Cerda, los diputados Latcham y Rossetti, cansados del semanal, propusieron el siguiente proyecto de Ley: "Se castigará ... a los que propaguen o fomenten de palabra o por escrito... doctrinas que preconicen la preeminencia de una raza sobre otra... o recomienden, inciten o induzcan a la persecución social o política de una o más razas determinadas", porque no creyeron conveniente para una convivencia pacífica que este antisemitismo continuara y se acentuara más

41 La Patria, 10 de junio de 1939.

42 Farías, Los Nazis en Chile, 257. 
cada día. Este proyecto el semanario La Patria lo llamó "macabro" y "un verdadero atentado a la chilenidad". Los judíos, según el diario se habían valido de dos "inmorales parlamentarios". Pensaron además que este proyecto de ley, absurdo y anti chileno no podría ser aprobado por una mayoría sensata. El semanal hizo un llamado al pueblo de Chile de que debían impedir el paso de una ley como ésta porque ellos deseaban la paz, pero si los arrastraban a la guerra irían a la guerra. Atacar a los hebreos y a sus defensores parecía ser la finalidad de este semanario.

Durante este tiempo el partido Social Fascista planeó una concentración. Su semanario La Patria hizo un llamado a todos los chilenos a asistir, pero el gobierno del Frente Popular impidió esta manifestación, además prohibió que el semanario se publicara durante más de cuatro semanas a causa de su racismo. Comenzó a aparecer nuevamente el 20 de diciembre de 1939 quejándose de esta actitud del gobierno, y en su ejemplar del 12 de febrero de 1940 culpó a los judíos de que su semanario hubiera sido cerrado: "El Partido Nacional Fascista para salvar a Chile, ha tenido que verse humillado por el judaísmo que ha empezado a acaparar todas las imprentas". (Firmado por Vásquez.) Y nuevamente acusó al gobierno del Frente Popular que permitía la entrada a tantos hebreos.

El Diario Ilustrado, católico, el 6 de mayo de 1940 escribió que nuestra capital estaba llena de extranjeros llegados a Chile en los últimos meses y que trabajaban en negocios intermedios y del comercio, sin desarrollar tareas verdaderamente productivas para nuestra economía. Los que fueron trasladados al sur habían vuelto a Santiago a vivir y competían con el comercio ya establecido desde hacía muchos años, porque reducían al mínimo los costos con su propio trabajo y eliminaban los medios de existencia a un número considerable de empleados o negocios subalternos. Y el 28 de diciembre del mismo año el periódico arriba mencionado escribió: “Judios amenazan anular completamente comercio chileno en Temuco".

Recordemos que Leiswitz, en su informe al gobierno alemán, había escrito algo muy diferente. Este tema de la entrada de los hebreos y como consecuencia, el problema de un posible desplazamiento del chileno, se debatía también en el parlamento. El diputado López se oponía a la inmigración judía por la competencia económica: "en mi barrio había un conciudadano que se 
dedicaba a la compra de botellas. Se instaló un semita... hizo fracasar al chileno... lenta y seguramente desplazan al comerciante chileno".

El diputado Benjamín Claro se oponía a que el inmigrante viviera en Santiago. Debía radicarse desde el Bío Bío al Sur y allí ejercer su comercio, su industria o la actividad que le pareciera y si eso no le gustaba debía quedarse en su país. El diputado Godoy señaló las dificultades de la inmigración y si Chile quería favorecer a este grupo con características especiales reconocidas universalmente, arrastrándose desde el fondo de los siglos, Chile necesitaba estudiar este problema y no resolverlo con simples medidas de orden policial dictadas ligeramente. ${ }^{43}$

En las calles céntricas de Santiago, de acuerdo a Mundo Judío, el partido naci-fascista chileno también daba sus comentarios antisemitas y en contra del gobierno. Cuenta un articulista del periódico que delante de la casa de un diario local grupos de personas comentaban las noticias de la guerra expuestas en un pizarrón. Se habían formado tres grupos y en cada uno de ellos un señor explicaba en voz alta que la invasión a Holanda y Bélgica por los alemanes era justa y lógica, los alemanes tenían el derecho de defenderse ante "el imperialismo judío". Y a continuación un discurso sobre los hebreos en Chile que acaparaban todos los bienes nacionales, compraban de los chilenos sus negocios y sus industrias. Los chilenos ya no tenían que hacer en su país, los israelitas se lo llevaban todo. Y comenzaban a criticar al gobierno, que éste es culpable, y mientras no se tenía un gobierno totalitario fascista, la situación crítica del país no tendría remedio. Según el articulista se trataba de la quinta columna que existió en todos los países de la América Latina. ${ }^{44}$

Interesante es que Chile fue el último país en Latino América en romper relaciones con los países del Eje.

Jose Dvoredzky Roitman en su artículo "The Jewish Experience in Chile: One Man's Recollection" dice que la noción de que los judíos mataron a Jesucristo existía aún en diversos

43 Mundo Judío, 4 de enero de 1940, 3

44 Mundo Judío, 17 de mayo de 1940, 3. 
sectores de la sociedad chilena. Sin embargo la clase media con quienes los judíos tuvieron más contacto, aceptó al israelita y expresó en general poco antisemitismo. Y eso es lo que también dijeron mis entrevistados.

Aquí algunos comentarios de mis entrevistados, inmigrantes judíos, los que vivieron en Santiago, la capital, donde los chilenos estaban acostumbrados a ver extranjeros: M. S. que llegó a Chile a fines de 1939 y asistió al Liceo $\mathrm{N}^{\circ} 7$ dijo que habían muchos inmigrantes y nunca nadie dijo nada en contra de los judíos. H. L. pensó que en Chile se adoraban a los extranjeros europeos y que los chilenos no hacían diferencia entre los alemanes arios y los alemanes judíos. G.G. sintió antisemitismo una sola vez, al cobrarle a una persona que le debía dinero. B. H. Estudió en los liceos $\mathrm{N}^{\circ} 5 \mathrm{y} \mathrm{N}^{\circ} 3$ y en ambos la recibieron muy bien, nunca se burlaron de ella por su acento o porque vestía diferente. No encontró antisemitismo, todo lo contrario, trataron de ayudarle y las compañeras la invitaban a sus casas, sobre todo cuando las tareas eran difíciles. El Señor K. encontró trabajo después de haber estado solo tres días en Santiago para arreglar las vitrinas de todas las zapaterías Mingo. No hubo nunca ningún antisemitismo, solo amistad. Él iba a la casa de los Mingo a comer, a jugar con los niños y siempre fue tratado muy bien. M. K. dijo que no existía antisemitismo de parte de los chilenos, que son muy hospitalarios y que respetan a los extranjeros. Había nazis en Santiago que frecuentaban El Renania, pero uno no tenía por qué meterse allí. El recuerda que las actividades antisemitas estaban prohibidas por el gobierno.

E. S. no pudo practicar medicina legalmente por no haber podido conseguir la nacionalidad chilena. (Cuando González Videla asumió la presidencia en 1946, conseguir la ciudadanía chilena para judíos fue imposible) Abrió una oficina médica ilegal en Santiago. Sus colegas chilenos sabían de ésto, pero lo dejaron ejercer y nunca lo acusaron a las autoridades. Ellos firmaban recetas médicas en blanco que el doctor Stark llenaba más adelante. Su esposa alabó la maravillosa característica de sus colegas chilenos, diciendo que en ningún otro país los médicos lo habrían dejado practicar o lo hubieran ayudado, siendo el un joven inmigrante judío. Solo los chilenos son capaces de comportarse así, pensó ella, que los chilenos eran únicos en su bondad y generosidad. 
Según R. N. los judíos eran respetados, el Nazismo era tan nuevo en Chile, que los chilenos no sabían la diferencia entre alemanes arios y alemanes judíos. R. N. no sintió antisemitismo, pero conoció a un niño judío que iba al Colegio Suizo y un día ya no quiso ir más. Iban a ese colegio muchos alemanes arios, que tal vez lo molestaron. Ruth trabajo para una familia chilena durante seis años y la niña la llamaba "abuelita." La trataron muy bien. Contó también que cuando llegó de Alemania a Valparaíso, llevaron a todo el grupo a Valdivia. Al pasar por Temuco a medianoche, los chilenos los recibieron con abrazos, vino y empanadas. Los sorprendió esta manera tan afectuosa de los chilenos de recibirlos, tan diferentes a la de los alemanes. Resultó ser el Año Nuevo. A. M. W. asistió al Liceo $\mathrm{N}^{\circ} 3$ y al Liceo $\mathrm{N}^{\circ}$. La admiraban en el colegio, era interesante por ser diferente, las compañeras la invitaban a sus casas o a sus fundos. Se sentía especial y le gustaba contar su historia. Para ella su contacto con los chilenos fue excelente. Su comentario sobre el chileno: "si le tocas el timbre y está comiendo, te invita a comer."

Entrevisté a una persona que llegando a Valdivia sintió antisemitismo porque era una ciudad donde habitaban muchos alemanes arios y en cuya plaza flameaba una bandera alemana con una swástica. Su padre, un farmacéutico no encontró trabajo en la farmacia, la que pertenecía a un alemán ario, quién temía que al emplearlo perdería su clientela alemana aria.

Mencionamos la Quinta Columna, o sea, espías alemanes que entraban y salían de Chile y otras naciones en Latinoamérica haciéndose pasar por turistas, hombres de negocios o artistas con nombres y pasaportes falsos, protegidos por consulados y embajadas alemanas y alemanes importantes. ${ }^{45}$ Los Estados Unidos habían interceptado un número de mensajes inalámbricos de agentes planeando sabotajes a barcos británicos y una invasión a Sur América después de ganar la guerra en Europa. ${ }^{46}$ Residentes que vivían en la costa del sur informaban haber visto destellos de submarinos y hubo rumores de grupos de alemanes entrando a regiones sureñas y recogiendo

45 New York Times, 4 de noviembre de 1942.

46 New York Times, 9 de junio de 1940, 6 y 4 de noviembre de 1942, 19; Farias, Los Nazis en Chile, 2:169-72 y $1: 288-89,299$. 
armas, pero nunca se comprobó. ${ }^{47}$

Ya hablamos de una diferencia entre Chile y otros países de Latinoamérica, la elección de Pedro Aguirre Cerda que llegó al poder a fines de 1938 y abrió las puertas a la inmigración judía. Hay una segunda diferencia. Chile recibió un gran número de alemanes arios en las décadas de 1850 y 1860 que tuvieron una gran influencia en este país ya antes de Hitler, y una aún mayor cuando él subió al poder. Chile los necesitaba para poblar las regiones del Sur, especialmente entre el Bío Bío y el estrecho de Magallanes. Así este territorio se pobló casi exclusivamente con alemanes arios. Era importante para ellos conservar su cultura e idioma y sus tradiciones, por eso sus hijos se casaban entre ellos. Necesitaban mantener su "alemanidad." Los matrimonios mixtos ocurrían más bien en los centros urbanos y mineros del norte donde la asimilación con la población chilena era más fácil. ${ }^{48}$

En 1909 Valdivia se convirtió en el segundo centro industrial del país, después de Santiago gracias a los alemanes arios, con sus cervecerías, destilerías, fábricas de calzado, cuero y ladrillos y sus compañías eléctricas. Sus métodos agrícolas eran más modernos que los usados por chilenos, estaban produciendo el cincuenta por ciento de la mantequilla nacional, un sexto de la carne y todo el cuero que se necesitaba en la industria valdiviana. ${ }^{49}$

En lo económico los alemanes tuvieron un gran impacto en Valdivia y la región de los lagos donde controlaban $70 \%$ de las propiedades y en Osorno donde el dominio era del 90\%. También tenían importancia en el gobierno local y estaban a cargo de establecimientos económicos claves en el Sur. ${ }^{50}$ Como ejemplo de ello está el caso del cementerio alemán de Valdivia que se hallaba situado a pocas cuadras de la Estación de Ferrocarriles, en plena calle Picarte y frente al Parque Municipal. Se pidió su traslado, pero los muertos no se movieron porque en la Municipalidad había dos regidores abiertamente partidarios de los alemanes, y el alcalde se sentía dominado por

47 La Hora, (Santiago de Chile), 2 de abril de 1939; Farias, Los Nazis en Chile, 269; New York Times, 13 de julio de 1940.

48 Converse, Christel Krause. (1990). "The Rise and Fall of Nazi Influence among the Greman-Chileans”, tésis doctoral, Georgetown University, U.S. A.

49 Converse, "Rise and Fall of Nazi Influence", 5-9.

50 Ibídem. 
ellos. ${ }^{51}$ La población de Valdivia y Osorno era durante los años treinta germana en casi su totalidad y el español se escuchaba difícilmente. ${ }^{52}$

Existieron grandes comunidades alemanas en las principales ciudades del país. Saltaban a la vista sus nombres en los negocios y compañías más importantes en las calles de Valparaíso, lo mismo pasaba en Santiago y otras ciudades. Se contaba la historia que cuando un nuevo alcalde llegó a Frutillar se encontró con que todos los documentos habían sido escritos en alemán y no podía entender quiénes habían pagado impuestos y quiénes no, fechas de nacimiento o si las personas estaban casadas, vivas o muertas. En Puerto Varas la mayoría de los hoteles y negocios tenían nombre alemán, igual que las líneas de buses y barcos y la guía de teléfonos estaba llena de nombres germanos. Y la posición política de todos estos alemanes nacidos en Chile según el autor Hubert Herring, fue que la mayoría era leal a Hitler. ${ }^{53}$

Los alemanes eran muy admirados y había una gran simpatía por ellos, sobre todo entre los militares, que cuando se supo la noticia de la muerte de Hindenburg, el presidente de la República de Weimar en Alemania, el 2 de agosto de 1934, un profesor de química en la Escuela Militar de Santiago pidió a los alumnos que se pararan y guardaran un minuto de silencio. Habló de lo mucho que los germanos habían contribuido a nuestra patria. ${ }^{54}$

Al subir Hitler al poder, muchos alemanes se convirtieron en grandes admiradores del Führer, no tanto por ser antisemitas, pero por querer un jefe fuerte. Habían estado desilusionados con la República de Weimar, por su división, desengañados con la derrota del imperio. Consideraban el Tratado de Versalles injusto. Las noticias que recibían de la República de Weimar, su inflación, su desempleo, las luchas en las calles, los asesinatos políticos los tenían desesperanzados. Querían sentirse orgullosos de su país y de ser alemanes. Hitler les daba ese orgullo. Los alemanes y sus descendientes que se unieron al partido lo hicieron por razones emocionales más

51 Las Noticias de Última Hora (Santiago de Chile), 4 de noviembre de 1943.

52 El Mercurio (Santiago de Chile), julio de 1930.

53 Herring, Hubert. (1940). Chile en la Presidencia de Don Pedro Aguirre Cerda. Santiago de Chile: Editorial Francisco de Aguirre). 143-48

54 Farias, Los Nazis en Chile, 375. 
que por principios políticos. ${ }^{55}$

Con una guerra mundial inminente, el Tercer Reich hizo todo lo posible para establecerse en Latinoamérica. Al no poder instalarse en Brasil, vieron a Chile como la segunda posibilidad, un país estratégicamente importante, ya que necesitaban una base de operaciones en varios lugares de América Latina para sus fuerzas navales, aéreas y de tierra, listas para combatir a los Estados Unidos en caso de que ganaran en Europa.

Los expertos náuticos coincidieron que las costas del Sur de Chile y el Estrecho de Magallanes, con sus numerosas bahías escondidas, ofrecían un escondrijo a submarinos y cruceros, además de encontrarse en sus regiones gran cantidad de provisiones. Importante era también que en el Sur de Chile vivían decenas de miles de alemanes quienes en la Primera Guerra se distinguieron por el apoyo a su país. Si se destruyera el Canal de Panamá, los alemanes a lo largo del Estrecho de Magallanes y en las Azores, tendrían control del transporte en el Sur como también en el Norte del Atlántico.

Esto parecía posible porque al comienzo de la Segunda Guerra Mundial tres generaciones de alemanes arios ya habían vivido y prosperado en Chile y continuaban hablando alemán, manteniendo su cultura y siendo leales al Reich. Tenían sus propias escuelas, sus propias iglesias, sus organizaciones y sus periódicos y escuchaban programas transmitidos desde Alemania. En 1941 había en Chile 20.000 alemanes arios nacidos en Alemania y 40.000 de sus descendientes. 56

Además de la introducción del NSDP (el Partido Nacional Socialista de Alemania) se crearon los Partidos Nacional Socialistas de Sur América que se originaron a principios de 1932 por el gran poder que en ese entonces gozaba el Partido Nacional Socialista de Alemania, apoyado por algunos de los más ricos industriales del Reich. Así el Movimiento Nazi penetró a la población nativa con su ideología fascista, aumentando el comercio entre Alemania y Sur América que era

55 Converse, "Rise and Fall of Nazi Influence", 125

56 Converse, "Rise and Fall of Nazi Influence", capítulo 1. 
mayor al que tenían con Gran Bretaña o los Estados Unidos. Trajeron una gran cantidad de propaganda Nacional Socialista con el intercambio. Los dirigentes del Nacismo Chileno (escrito con "C" para diferenciarlo del alemán) fueron alemanes chilenos que en un principio trabajaron en cooperación con Berlín. El 2 de abril de 1937, el periódico alemán Frankfurter Zeitung anunció que el Partido Nacista en Chile tenía entre cuarenta y cincuenta mil socios.

La población alemana estaba de acuerdo con el programa de antisemitismo, aunque un gran número de los alemanes chilenos estaba en contra de las doctrinas raciales de Hitler. Las escuelas alemanas ya existían en Valdivia desde 1858. Durante el período de Hitler, enseñaban en ellas profesores venidos de Alemania con ideas nazistas. Los alumnos saludaban con el brazo en alto el retrato del Führer y se celebraba su cumpleaños y el de Goering. Se les instruía a los alumnos en la importancia de su descendencia alemana y en la superioridad de su "raza".

El periódico Aurora de Chile pensó que este país debía acabar con estas escuelas extranjeras que desnacionalizaban a niños nacidos en Chile, enseñándoles ideas antidemocráticas, no respetando ni la historia del país, ni el idioma ni la bandera, pues los niños estudiaban la historia de Alemania y el idioma alemán, aprendían símbolos extranjeros e ideas totalitarias. ${ }^{57}$

Seguían el mismo programa de estudios del Reich, porque los colegios recibían ayuda de dinero y algunos profesores nazis ejercían presión. En 1935 el número de estas escuelas en Chile llegaban a cincuenta y dos, seis en Santiago y cuatro en los alrededores y la mayoría en el sur con una asistencia de cinco mil estudiantes. Los profesores provenían de Alemania y su tarea principal era combatir la asimilación. ${ }^{58}$

Pero habían ciudadanos en el Sur que querían que sus hijos aprendieran bien el español para tener éxito en Chile, así los matricularon en escuelas secundarias chilenas. "Estamos en Chile" decían, recomendándoles a sus hijos ser buenos chilenos.

57 Aurora de Chile (Santiago de Chile), 5 de junio de 1939.

58 Converse, "Rise and Fall of Nazi Influence", 172; y Farias, Nazis en Chile, 51, 76. 
La infiltración nazi se sentía en toda Latino América, no solamente en Chile. Lo alarmante era que políticos chilenos ayudaban y protegían a los agentes y a la vez les daban información, y los alemanes abusaban de la hospitalidad del gobierno chileno. ${ }^{59}$ Muchas empresas alemanas financiaban las actividades de espionaje. ${ }^{60}$

La influencia e infiltración del Nacional Socialismo alemán en Chile fue algo impresionante, según Víctor Farías en su libro Los Nazis en Chile, especialmente en la Aviación, las Fuerzas Armadas, la Marina y los Carabineros, pero también en otras instituciones. Esto fue posible por el aprecio y el intercambio que existía ya por mucho tiempo entre los dos países y por la gran admiración de los chilenos por los alemanes. En 1935, el General Arriagada, jefe del Cuerpo de Carabineros de Chile, deseó enviar a Alemania a algunos oficiales chilenos para conocer en detalle la organización de la policía de ese país, le comunicó a su anfitrión que sus oficiales simpatizaban fuertemente con el ejército alemán y también con sus ideas raciales. ${ }^{61}$ No nos debía haber sorprendido que al celebrar el "Deutsche Militaers Verein" su aniversario en ese mismo año, que encontráramos invitados allí a un gran número de oficiales del ejército, la marina y los carabineros, junto a las personas más importantes del Partido Nacional Socialista Alemán. ${ }^{62}$

Algunos chilenos de gran influencia apoyaban la causa alemana, entre ellos, Ross, el pasado Ministro de Finanzas y en 1938 candidato a la presidencia, quién invitado por el gobierno alemán pasó largo tiempo en ese país en 1937. Asimismo Miguel Cruchaga, ex Ministro del Exterior y en 1938 Presidente del Senado y del Instituto Chileno-Alemán de Cultura y el General Ibáñez, candidato presidencial de los nacis chilenos en ese mismo año era conocido como partidario de Hitler. Numerosos oficiales chilenos fueron entrenados en el Reich y oficiales prusianos fueron los instructores en los ejércitos de Latinoamérica por más de una generación.

Asimismo en la Universidad casi no había facultades que no tuvieran profesores alemanes, especialmente en la década de los veinte y treinta, sobre todo la Escuela Normal y el Pedagógico,

59 El Diario Ilustrado (Santiago de Chile), 24 de febrero de 1944.

60 Farías, Nazis en Chile, 319.

61 Ibídem, 402-3.

62 Ibídem, 377 
cuyos fundadores fueron especialistas alemanes en $1889 .{ }^{63}$

El jefe del Movimiento Nacional Socialista Chileno mencionado arriba, Jorge González von Marées, cuyas ideas en un principio fueron las mismas de la Alemania hitlerista pero fueron cambiando y diferenciándose de las de los nazis alemanes. Ya mencionamos que la elección de Pedro Aguirre Cerda se debió al voto de este movimiento. En una reunión política en que los Nacis chilenos celebraron la victoria de Aguirre Cerda el 4 de diciembre de 1938 condenaron la furia anti-semita de Hitler. Su jefe González von Marées había declarado anteriormente que los nacis chilenos (con "c" en vez de "z") eran diferentes de los nazis alemanes. Él quería un movimiento nativo, no anti-semita, porque en Chile no había un problema judío, según él.

En el segundo congreso del partido Nacional Socialista Chileno, el 14 de enero de 1939, su jefe dijo algo muy importante para los judíos: que ellos no eran fascistas... en su origen se inspiraron en el fascismo, pero más adelante éste se convirtió en sinónimo de tiranía, persecución y luchas raciales... y "a nosotros" no nos interesa ni el Fascismo ni el Hitlerismo. Tenemos nuestras propias formas y no tenemos porqué aceptar formas extranjeras... ${ }^{64}$ Cuando González fue elegido al Parlamento en mayo de 1937, criticó la Alemania de Hitler, distanciándose más y más de los Nazis alemanes. En una reunión en Valdivia atendida por muchos alemanes chilenos, González los criticó porque se resistían a incorporarse a la nación chilena, y en vez de honrar la bandera de Chile, país donde habían vivido por generaciones, rehusaban a aprender español y daban homenaje a la swástica. Los alemanes estaban indignados. ${ }^{65}$

Es posible que por todos estos cambios del Movimiento Nacional Socialista Chileno, cuando llegó la mayoría de inmigrantes judíos alemanes, ellos ya no tuvieron que enfrentar a los Nacis marchando en las calles con uniformes y swásticas. El gobierno lo había prohibido. El movimiento desapareció en 1942.

63 Ibídem, 361.

64 Trabajo, 15 de enero de 1939.

65 Klein, Marcus. (2004). "The Chilean Movimiento Nacional Socialista, The German Chilean Community and the Third Reich, 1932-1939: Myth and Reality.” The Americas, (60), 609-611. 


\section{Conclusión}

Chile ocupa un lugar especial en la experiencia judía durante los años del Holocausto. No por el número de judíos que entró al país, sino por el hecho que justo cuando las puertas de otros países se cerraban en un momento tan crítico para los inmigrantes israelitas, el Presidente de Chile, Pedro Aguirre Cerda, acogió a los refugiados del Nacismo en su país para darles una oportunidad de rehacer sus vidas.

A pesar de la gran cantidad de alemanes étnicos que habían entrado al país a mediados del siglo XIX y a pesar de que éstos tenían una gran admiración por Hitler cuando éste subió al poder, la política racial de Hitler nunca fue aceptada completamente en Chile y los refugiados judíos encontraron su lugar dentro de la sociedad y la economía chilena. La mayoría de los inmigrantes israelitas a quienes entrevisté me aseguraron que en la clase media con quienes ellos trataron

encontraron mucha hospitalidad, buena voluntad en ayudarles y poco antisemitismo. El Presidente Pedro Aguirre Cerda fue en realidad un gran amigo de los judíos como también lo fueron los grandes poetas Pablo Neruda y Gabriela Mistral.

\section{Bibliografía}

Archivo Nacional de Chile, Ministerio de Relaciones Exteriores.

Aurora de Chile (Santiago de Chile), 5 de junio de 1939.

Böhm, Günter. (1994). Judíos en Chile: un informe confidencial de la Embajada Alemana en Santiago, junio de 1939. Proceedings of the Eleventh World Congress of Jewish Studies 1993. XI.

Converse, Christel Krause. (1990). "The Rise and Fall of Nazi Influence among the GremanChileans", tésis doctoral, Georgetown University, U.S. A. 
El Diario Ilustrado (Santiago de Chile), 24 de febrero de 1944.

El Mercurio (Santiago de Chile), julio de 1930.

Farías, Víctor. (2000). Los Nazis en Chile. Barcelona, España: Editorial Seix Barral.

Guggenheim, Carlos. (1942). Refugiados-Inmigrados-Nuevos Chilenos. Santiago de Chile: Imprenta la sudamericana.

Herring, Hubert. (1940). Chile en la Presidencia de Don Pedro Aguirre Cerda. Santiago de Chile: Editorial Francisco de Aguirre). 143-48

Klein, Marcus. (2004). "The Chilean Movimiento Nacional Socialista, The German Chilean Community and the Third Reich, 1932-1939: Myth and Reality". The Americas, (60), 609-611.

La Hora. 2-12 de marzo 1939 / 2 de abril de 1939. Santiago de Chile.

Leiken, Judith. (1987). The Jewish Presence in Latin America. Boston, MA: Allen and Unwin.

Lesser, Jeffrey. (1995). Welcoming the Undesirables, Brazil and the Jewish Question. Berkeley: University of California Press.

La Patria (Santiago de Chile). 10 de junio de 1939.

Las Noticias de Última Hora (Santiago de Chile), 4 de noviembre de 1943.

Levine, Robert M. (1987). "Adaptive tragedies of Jews in Latin America". In J. Leiken and G.W. Merkx (Eds.), The Jewish Presence in Latin America. Boston, MA: Allen an Unwin.

Levy, Robert. (1948). El verdadero aporte a la economía chilena. Judaica, 166. 
Eva Goldschmidt

Inmigración judía a Chile...

Levy, Robert. (1938) Judíos en la Economía Nacional Chilena.

Mundo Judío, 3 de noviembre, 1938, 11 / 4 de enero - 17 de mayo de 1940, 3.

Nes-El, Moshe. (1982). “Inmigración Judía a Chile durante 1929-1939.” Coloquio, 4, 85-86.

New York Times. 17 de julio 1940, 11 / 5 de enero 1941, 33 / 6 y 4 de noviembre 1942, 19.

US Holocaust Museum Encyclopedia, www.ushmm.org/wlc/en/article.php? ModuleId= 10007824 citado $16 / 7 / 2015$

Weinfeld, Eduardo. (1940). El Antisemitismo en la América Latina. Judaica, 83, 201-208.

Wojak, Irmtrud. (1994). Exil in Chile. Berlin, Germany: Metropol Verlag. 